ten besonders in einer Reihe von Landtagen in Erscheinung, wo die politischen Führer zugleich den Kasten der landbesitzenden Farmer angehören. Diese Vermengung von politischen mit wirtschaftlichen Interessen auf seiten der regionalen Kongreßführung ist auch eine wesentliche Ursache für die mangelnde Effiziens der Agrarreformen gewesen ${ }^{3}$.

Doch ist dieses Buch eine Querschnittanalyse und hat daher wie jedes Werk dieser Art seine Lücken. Diese fallen jedoch nicht so ins Gewicht, weil die Untersuchung über die spezifisch politischen Probleme in sich geschlossen ist. So wird von Wirsing auch richtig gesehen, daß die reibungslose Lösung der Nachfolge Nehrus und Shastris die Vitalität der Demokratie auf indischem Boden unter Beweis gestellt hat, zumal die außerparlamentarischen Kräfte auch indirekt nicht einwirkten. Ebenso bedeutete die Niederlage der Kongreßpartei in den vierten allgemeinen Wahlen (Februar 1967) im Grunde eine Stärkung für den indischen Parlamentarismus. Sie brachte der Opposition die Chance der Machtbildung in einer Reihe von Landtagen, während sich die Kongreßpartei dort mit der Rolle einer Opposition begnügen mußte. Allerdings ist die Kongreßpartei die einzige Partei von gesamtindischer $\mathrm{Be}-$ deutung geblieben. Aber sie wird, wie Wirsing meint, fortan den Begriff der Koalition in ihr Kalkül einbeziehen müssen.

Der Verfasser vertritt mit Recht die Auffassung, daß sich Indien in einer Epoche des Übergangs befindet. Man hat in dieser Periode erkennen müssen, $\mathrm{da} ß$ es auch einen asiatischen Imperialismus gibt, einen Imperialismus kommunistischer Prägung. Dieser Erkenntnis hat, wie Wirsing im Schlußkapitel seines anregenden und empfehlenswerten Buches feststellt, nicht zuletzt den Prozeß des Umdenkens beschleunigt, der, wie in Japan, zu einem neuen Selbstverständnis führen wird. Dem interessierten Leser wird so begreiflich, in welchen historischen Dimensionen die Entwicklung in Indien zu bewerten ist. Dem Autor ist aber zu danken, daß er dafür die Maßstäbe richtig gesetzt hat. Aber auch für ihn muß die Frage offenbleiben, ob es Indien gelingen wird, die innenpolitischen Probleme mit den Mitteln der Demokratie zu lösen.

Horst Hartmann

\section{Judith Listowel}

\section{The Making of Tanganyika}

2. Aufl., Chatto und Windus, London 1968, XIX, 451 S., $50 \mathrm{sh}$.

Die Verfasserin dieser Geschichte Tanganyikas war urspünglich Journalistin. Sie ist auf diesem Umweg zur Historie gekommen, und ihrer umfassenden Geschichte Tanganyikas kommt die journalistische Feder insoweit zugute, als das Buch nicht nur sehr lesenswert, sondern auch lesbar ist, weshalb es jetzt schon in der 2. Auflage vorgelegt wird.

Die Geschichte Tanganyikas stellt die Verfasserin dar an Hand der Entwicklung der führenden und bestimmenden Persönlicheiten der einzelnen Epochen. Den ihrer Meinung nach bedeutendsten Persönlichkeiten der Geschichte Tanganyikas, nämlich dem derzeitigen Präsidenten Nyerere und dem vormaligen Gouverneur Sir Richard Turnbull hat sie dieses Buch auch gewidmet. Die Orientierung des Geschichtsbildes auf die führenden Persönlichkeiten und ihr Leben gibt dem Buch seine Lebendigkeit und seine Anschaulichkeit, getragen von einem starken persönlichen Engagement der Autorin für ihre Helden. So findet sich in dem Buch fast ein Epos auf den großen Häuptling Mkwaba, der am Ende vergeblich gegen die Deutschen ankämpfte. General Lettow-Vorbeck begeisterte die Autorin kaum weniger, und sie rügt die Bundesrepublik Deutschland, daß sie die-

3 Es ist daher auch wohl nicht ganz zutreffend, wenn in einer Besprechung dieses Buches die Auffassung vertreten wird, daß die Folgen des Kastenwesens nicht so sehr auf dem wirtschaftlichen wie auf der politischen Gebiet liegen. Siehe die Rezension von Wilhelm von Pochhammer, in Indo Asia, Stuttgart Juli 1968, S. 287. 
sem Mann nicht einen anständigen Ehrensold gegeben habe. Die britischen Gouverneure Sir Donald Cameron und Sir Edward Twining, aber auch Julius Nyerere und seine Freunde sind die Helden der historischen Bühne der Verfasserin. Eingeflochten in diese $\mathrm{Ge}-$ schichte sind die einzelnen Vorgänge in Tanganyika, die Gründung der TANU und ihr Kampf um die Macht, die Finanzprobleme des Staates, die Aufgaben, denen sich die politische Führung heute gegenübersieht, aber auch die Probleme, mit denen die europäischen Mächte Deutschland und Großbritannien in Tanganyika zu kämpfen hatten. Die Verfasserin legt dar, daß England aus dem deutschen Konglomerat ostafrikanischer Stämme das Land Tanganyika gemacht habe; sie behandelt das Problem der weißen Siedler und ihre Forderung auf Sicherung ihrer Existenz, das sowohl die britische Verwaltung als auch die Afrikaner lange Zeit beschäftigt hat. Sie stellt den Kampf zwischen den jungen Intellektuellen und den alten Häuptlingen dar. In all dem zeigt sie immer wieder menschliche Probleme und persönliche Konflikte der einzelnen handelnden Personen auf.

Das Buch ist eine sehr persönliche $\mathrm{Ge}$ schichte Tanganyikas und hat vielleicht gerade deshalb bisher eine so große Leserschaft gefunden. In Anbetracht der Tatsache, daß in vielen der neuen Staaten, auch in Tansania, die Persönlichkeit eines einzelnen Politikers oft die staatliche Ordnung prägt und an Bedeutung überragt, ist eine solche personale Darstellung eines Staates dem Gegenstand durchaus angemessen. Für diese Zeitschrift und ihre Leser dürfte besonders das Kapitel über den Aufbau und die Ziele des Schulwesens in Tanganyika von Bedeutung sein. Die Verfasserin stellt es unter das Motto: "A due supply of persons well qualified to serve." Dieses Motto ist dem Schulgebet englischer Public Schools und University-Colleges entnommen, in dem es heißt: "And that there may never be lacking a due supply of persons well qualified to serve Thee, in church and state" (S. 85). Die Verfasserin beschreibt in ihrer engagierten Weise, wie unter dem Gouverneur Cameron in Tanganyika das Schulwesen aufgebaut wurde, mit dem Ziel, Staatsdiener und Staatsbürger zu erziehen. Sie beschreibt die Probleme, die auftraten, als es darum ging, die zukünftigen Beamten aus ihrer Stammesverbundenheit $\mathrm{zu}$ lösen und ihnen den Sinn eines Gemeinwesens und eines Gemeinwohls verständlich zu machen. Sie beschreibt die Erfolge dieses Schulsystems, das schließlich seine Krönung erfuhr, als mit Julius Nyerere ein Schüler und Lehrer einer dieser Schulen in Tanganyika Präsident des unabhängig gewordenen Landes wurde, womit sich der Sinn dieses Erziehungssystems erfüllte. Am Schluß dieses Kapitels steht ein Zitat aus einer Rede Nyereres, in dem er die Bedeutung der Erziehung für einen neuen Staat darlegt und die Schule als einzigartige Ausbildungsstätte für die politische Führung des Landes bezeichnet.

Dieses Buch, das für unsere Maßstäbe sicherlich nicht wissenschaftlich analytisch genug vorgeht, ist eines der lesenswertesten und in seinem Engagement wahrhaftigsten Bücher über Tanganyi$\mathrm{ka}$, ein Buch, dessen Lektüre man jedem empfehlen kann, auch wenn er nicht zum Kreise der "Tanzaphilisten" (Mazrui) gehört.

Dieter Schröder

Cecil V. CrabB, JR.

The Elephants and the Grass

A Study of Nonalignment

Frederick A. Praeger, New York, Washington, London 1965, XIII, 237 S., $5.50 \$$

Über Bündnisfreiheit und Neutralismus ist in den letzten Jahren viel geschrieben worden. Zunächst aus der Perspektive des westlichen oder östlichen Politikers, wobei oft im Westen Bündnisfreiheit als Desinteresse an Freiheit, Menschenwürde und Demokratie verstanden, während sie im Osten als eine Unterstützung der Politik „friedlicher Koexistenz" aufgefaßt wurde. Dem eigentlichen Wesen der Bündnisfreiheit 